\title{
Phytochemical characterization and antioxidant activity of the cladodes of Opuntia macrorhiza (Engelm.) and Opuntia microdasys (Lehm.)
}

Hassiba Chahdoura ${ }^{\mathrm{a}, \mathrm{b}}$, João C.M. Barreira ${ }^{\mathrm{a}, \mathrm{c}}$, Lillian Barros ${ }^{\mathrm{a}}$, Celestino Santos-Buelga ${ }^{\mathrm{c}}$, Isabel

C.F.R. Ferreira ${ }^{a}, *$, Lotfi Achour ${ }^{b}$

${ }^{a}$ Mountain Research Centre (CIMO), ESA, Polytechnic Institute of Bragança, Campus de Santa Apolónia, Ap. 1172, 5301-855 Bragança, Portugal.

${ }^{b}$ Laboratoire de Recherche "Bioressources": Biologie Intégrative \& Valorisation", Institut Supérieur de Biotechnologie de Monastir, Avenue Tahar Hadded, BP 74, 5000, Université de Monastir, Monastir, Tunisia.

${ }^{c}$ Grupo de Investigación en Polifenoles (GIP-USAL), Faculty of Pharmacy, University of Salamanca, Campus Miguel de Unamuno, 37007 Salamanca, Spain.

\footnotetext{
*Author to whom correspondence should be addressed (e-mail: iferreira@ipb.pt, telephone +351273303219$, fax +351273325405$)$.
} 


\begin{abstract}
The genus Opuntia (Cactaceae) includes different plants well adapted to arid and semi-arid zones. These species are cultivated under restricted growth conditions, not suitable for the growth of other fruits/vegetables. The cactus pear is a well-known example inside Opuntia genus. Its young cladodes, also known as nopalitos, are frequently consumed and used in folk medicine due to their beneficial effects and phytochemical composition. Herein, hydrophilic and lipophilic extracts from cladodes of Opuntia microdasys and Opuntia macrorhiza were characterized. Furthermore, their antioxidant properties were compared to the corresponding phytochemical profile. Despite the phylogenetic proximity and similar geographical origin $O$. microdasys and $O$. macrorhiza showed significant differences in sugars, organic acids, phenolic compounds, fatty acids and tocopherols profiles. In particular, O. microdasys distinguished for having high contents in fructose, glucose, C6:0, C8:0, C12:0, C14:0, C14:1, C16:0, C18:3, C20:0, C22:0, C23:0, C24:0, SFA and tocopherols, and also for its higher DPPH $\mathrm{EC}_{50}$ values. O. microdasys by its side proved to have significantly higher amounts of trehalose, organic acids, C13:0, C16:1, C17:0, C18:0, C18:1, C20:1, C20:2 and MUFA. The obtained phytochemical profiles might be considered as useful information to select the best Opuntia species regarding a determined application of its natural extracts/isolated compounds.
\end{abstract}

Keywords: Opuntia; Hydrophilic compounds; Lipophilic compounds; HPLC-DAD-ESI/MS. 


\section{Introduction}

The Opuntia spp. genus belongs to the Cactaceae family, from which the cactus pear is a well-known example. This plant is native from Mexico, being well adapted to arid and semiarid zones. It can be cultivated under restricted growth conditions that are not suitable for the growth of other fruits and vegetables. The young cladodes, also known as nopalitos, are consumed as vegetables. ${ }^{1}$ Cladodes are modified stems and replace the photosynthetic function of leaves. These succulent and articulate organs have an ovoid or elongated form (30 to $80 \mathrm{~cm}$ long and 18 to $25 \mathrm{~cm}$ wide). The inner part of the cladode is formed by the chlorenchyma, where photosynthesis occurs, and the inside part is formed by a white medullar parenchyma whose main function is water storage. ${ }^{2}$ Cactus in Tunisia is mostly localized in areas characterized by low quality soils and water scarcity. Actually, in Mediterranean countries, cactus pear plant grows spontaneously and is consumed exclusively as fresh fruit. Only a small quantity is being used for processing; so, there is the need of improving outlet for seasonally surplus production. ${ }^{3}$

It has also been useful in controlling desertification and improving depleted natural rangelands by preventing long-term degradation of ecologically weak environments. ${ }^{4}$

Cactus fruits and cladodes, especially those from Opuntia genus, have been widely used, in many countries, as food, source of vegetal nutrients, and in folk medicine. ${ }^{5,6}$ The young cladodes are rich in dietary fiber, ${ }^{7}$ carbohydrates, minerals, proteins and vitamins. Medical research has found value in cladodes as a raw material for products to treat high blood cholesterol levels, gastric acidity, blood pressure and several pathologies, such as ulcer, fatigue and rheumatism pain. ${ }^{8}$ It is claimed to be an excellent source of natural oligoelements which may improve human health and nutrition. ${ }^{1}$ Cactus pear extracts have shown antitumor ${ }^{9}$ and antioxidant activities. ${ }^{10}$ 
In this work, quantitative and qualitative aspects of Opuntia microdasys and Opuntia macrorhiza phytochemistry, two Opuntia species with close phylogenetic relationship ${ }^{11}$, were studied using hydrophilic and lipophilic extracts from cladodes further characterized by spectrophotometric and chromatographic techniques. The objective of this work was comparing the chemical composition of cladodes, regarding hydrophilic (sugars, organic acids and phenolic compounds) and lipophilic (fatty acids and tocopherols) molecules. Furthermore, in vitro antioxidant properties (free radicals scavenging activity, reducing power and lipid peroxidation inhibition) of their methanolic extracts were evaluated and compared to the corresponding phytochemical profile.

\section{Experimental}

\section{Samples}

Opuntia macrorhiza (Engelm.) and Opuntia microdasys (Lhem.) cladodes (2-3 years) were collected from the Cliff of Monastir (Tunisia) between June and July 2013. After spines removal, cladodes were washed, dried under shade, grounded with a Warring blender (Philips, France), reduced to a fine dried powder (20 mesh), mixed to obtain a homogenate sample and stored at $4{ }^{\circ} \mathrm{C}$.

\section{Standards and Reagents}

Acetonitrile (99.9\%), n-hexane (97\%) and ethyl acetate (99.8\%) were of HPLC grade from Fisher Scientific (Lisbon, Portugal). The fatty acids methyl ester (FAME) reference standard mixture 37 (standard 47885-U) was purchased from Sigma (St. Louis, MO, USA), as also were other individual fatty acid isomers and standards: L-ascorbic acid, tocopherols $(\alpha-, \beta-, \gamma-$ and $\delta$-isoforms), sugars $(\mathrm{D}(-)$-fructose, $\mathrm{D}(+)$-melezitose, $\mathrm{D}(+)$-sucrose, $\mathrm{D}(+)$-glucose, $\mathrm{D}(+)$ trehalose and $\mathrm{D}(+)$-raffinose pentahydrate), organic acids and trolox (6-hydroxy-2,5,7,8- 
tetramethylchroman-2-carboxylic acid). Phenolic compounds were purchased from Extrasynthèse (Genay, France). Racemic tocol, $50 \mathrm{mg} / \mathrm{mL}$, was purchased from Matreya (Pleasant Gap, PA, USA). 2,2-Diphenyl-1-picrylhydrazyl (DPPH) was obtained from Alfa Aesar (Ward Hill, MA, USA). Water was treated in a Milli-Q water purification system (TGI Pure Water Systems, Greenville, SC, USA). All other chemicals and solvents were of analytical grade and purchased from common sources.

\section{Chemical composition in hydrophilic compounds}

Sugars. Free sugars were determined by high performance liquid chromatography coupled to a refraction index detector (HPLC-RI). Dried sample powder $(1.0 \mathrm{~g})$ was spiked with melezitose as internal standard (IS, $5 \mathrm{mg} / \mathrm{mL}$ ), and was extracted with $40 \mathrm{~mL}$ of $80 \%$ aqueous ethanol at $80{ }^{\circ} \mathrm{C}$ for $30 \mathrm{~min}$. The resulting suspension was centrifuged (Centurion K24OR refrigerated centrifuge, West Sussex, UK) at $15,000 \mathrm{~g}$ for $10 \mathrm{~min}$. The supernatant was concentrated at $60{ }^{\circ} \mathrm{C}$ under reduced pressure and defatted three times with $10 \mathrm{~mL}$ of ethyl ether, successively. After concentration at $40{ }^{\circ} \mathrm{C}$, the solid residues were dissolved in water to a final volume of $5 \mathrm{~mL}$ and filtered through $0.2 \mu \mathrm{m}$ nylon filters from Whatman. ${ }^{12}$ The equipment of analysis consisted of an integrated system with a pump (Knauer, Smartline system 1000, Brelin, Germany), degasser system (Smartline manager 5000), auto-sampler (AS-2057 Jasco, Easton, MD) and an RI detector (Knauer Smartline 2300). Data were analysed using Clarity 2.4 Software (DataApex, Prague, Czech Republic). The chromatographic separation was achieved with a Eurospher $100-5 \mathrm{NH}_{2}$ column $(4.6 \times 250$ $\mathrm{mm}, 5 \mathrm{~mm}$, Knauer) operating at $30{ }^{\circ} \mathrm{C}(7971 \mathrm{R}$ Grace oven). The mobile phase was acetonitrile/deionized water, 70:30 $(v / v)$ at a flow rate of $1 \mathrm{~mL} / \mathrm{min}$. The compounds were identified by chromatographic comparisons with authentic standards. Quantification was 
performed using the internal standard method and sugar contents were further expressed in $\mathrm{g}$ per $100 \mathrm{~g}$ of dry weight $(\mathrm{dw})$.

Organic acids extraction and analysis. Organic acids were determined following a procedure previously optimized and described by the authors. ${ }^{13}$ Analysis was performed by ultra-fast liquid chromatograph (UFLC) coupled to photodiode array detector (PDA), using a Shimadzu 20A series UFLC (Shimadzu Coperation, Kyoto, Japan). Separation was achieved on a SphereClone (Phenomenex, Torrance, CA, USA) and detection was carried out in a PDA, using 215 and $245 \mathrm{~nm}$ as preferred wavelengths. The organic acids found were quantified by comparison of the area of their peaks recorded at 215 and $245 \mathrm{~nm}$ (for ascorbic acid) with calibration curves obtained from commercial standards of each compound. The results were expressed in g per $100 \mathrm{~g}$ of dry weight (dw).

Phenolic compounds extraction and analysis. The powdered cladodes $(\sim 1 \mathrm{~g})$ were extracted by stirring with $30 \mathrm{~mL}$ of methanol:water 80:20 (v/v), at room temperature, $150 \mathrm{rpm}$, for $1 \mathrm{~h}$. The extract was filtered through Whatman $\mathrm{n}^{\circ} 4$ paper. The residue was then re-extracted twice with additional portions $(30 \mathrm{~mL})$ of methanol:water 80:20 $(v / v)$. The combined extracts were evaporated at $35{ }^{\circ} \mathrm{C}$ (rotary evaporator Büchi R-210, Flawil, Switzerland) to remove methanol. The aqueous phase was lyophilized and the extracts were re-dissolved in $20 \%$ aqueous methanol at $5 \mathrm{mg} / \mathrm{mL}$ and filtered through a $0.22-\mu \mathrm{m}$ disposable LC filter disk for high performance liquid chromatography (HPLC-DAD-MS) analysis.

Phenolic compounds were determined by HPLC (Hewlett-Packard 1100, Agilent Technologies, Santa Clara, USA) as previously described by the authors. ${ }^{14}$ Double online detection was carried out in the diode array detector (DAD) using $280 \mathrm{~nm}$ and $370 \mathrm{~nm}$ as preferred wavelengths and in a mass spectrometer (MS) connected to the HPLC system via 
the DAD cell outlet. The phenolic compounds were characterized according to their UV and mass spectra and retention times, and comparison with authentic standards when available. For the quantitative analysis of phenolic compounds, a 5-level calibration curve was obtained by injection of known concentrations $(2.5-100 \mu \mathrm{g} / \mathrm{mL})$ of different standards compounds. The results were expressed in $\mu \mathrm{g}$ per g of extract (dw).

\section{Chemical composition in lipophilic compounds}

Fatty acids. Fatty acids were determined after a transesterification procedure as described previously by the authors, ${ }^{12}$ using a gas chromatographer (DANI 1000) equipped with a split/splitless injector and a flame ionization detector (FID at $260{ }^{\circ} \mathrm{C}$ ) and a Macherey-Nagel (Düren, Germany) column (50\% cyanopropyl-methyl-50\% phenylmethylpolysiloxane, $30 \mathrm{~m} \times$ $0.32 \mathrm{~mm}$ i.d. $\left.\times 0.25 \mu \mathrm{m} \mathrm{d}_{\mathrm{f}}\right)$. Fatty acid identification was made by comparing the relative retention times of FAME peaks from samples with standards. The results were recorded and processed using CSW 1.7 software (DataApex 1.7, Prague, Czech Republic). The results were expressed in relative percentage of each fatty acid.

Tocopherols. Tocopherols were determined following a procedure previously optimized and described by the authors. ${ }^{12}$ Analysis was performed by HPLC (equipment described above), and a fluorescence detector (FP-2020; Jasco, Easton, MD, USA) programmed for excitation at $290 \mathrm{~nm}$ and emission at $330 \mathrm{~nm}$. The compounds were identified by chromatographic comparisons with authentic standards. Quantification was based on the fluorescence signal response of each standard, using the IS (tocol) method and by using calibration curves obtained from commercial standards of each compound. The results were expressed in mg per $100 \mathrm{~g}$ of dry weight. 


\section{Antioxidant activity}

The methanolic extract (prepared according to section 2.3.3) was redissolved in methanol (final concentration $5 \mathrm{mg} / \mathrm{mL}$ ); the final solution was further diluted to different concentrations to be submitted to antioxidant activity evaluation by different in vitro assays as described in Pereira et al. ${ }^{12}$

DPPH radical-scavenging activity was evaluated by using a ELX800 microplate Reader (BioTek Instruments, Inc; Winooski, USA), and calculated as a percentage of DPPH discolouration using the formula: $\left[\left(\mathrm{A}_{\mathrm{DPPH}}-\mathrm{A}_{\mathrm{S}}\right) / \mathrm{A}_{\mathrm{DPPH}}\right] \times 100$, where $\mathrm{A}_{\mathrm{S}}$ is the absorbance of the solution containing the sample at $515 \mathrm{~nm}$, and $\mathrm{A}_{\mathrm{DPPH}}$ is the absorbance of the DPPH solution.

Reducing power was evaluated by the capacity to convert $\mathrm{Fe}^{3+}$ into $\mathrm{Fe}^{2+}$, measuring the absorbance at $690 \mathrm{~nm}$ in the microplate Reader mentioned above.

Inhibition of $\beta$-carotene bleaching was evaluated though the $\beta$-carotene/linoleate assay; the neutralization of linoleate free radicals avoids $\beta$-carotene bleaching, which is measured by the formula: $\beta$-carotene absorbance after $2 \mathrm{~h}$ of assay/initial absorbance) $\times 100$.

Lipid peroxidation inhibition in porcine (Sus scrofa) brain homogenates was evaluated by the decreasing in thiobarbituric acid reactive substances (TBARS); the colour intensity of the malondialdehyde-thiobarbituric acid (MDA-TBA) was measured by its absorbance at $532 \mathrm{~nm}$; the inhibition ratio (\%) was calculated using the following formula: $[(\mathrm{A}-\mathrm{B}) / \mathrm{A}] \times 100 \%$, where $\mathrm{A}$ and $\mathrm{B}$ were the absorbance of the control and the sample solution, respectively.

The results were expressed in $\mathrm{EC}_{50}$ value (sample concentration providing $50 \%$ of antioxidant activity or 0.5 of absorbance in the reducing power assay). Trolox was used as positive control.

\section{Statistical analysis}


All extractions were performed in triplicate and each replicate was also analysed in triplicate. The results are expressed as means \pm standard deviations. Results were classified using a simple $t$-test for equality of means (after checking the equality of variances through a Levene's test), since there were fewer than three groups. All statistical tests were performed at a 5\% significance level using the SPSS software, version 20.0 (IBM Inc).

\section{Results and Discussion}

\section{Chemical composition in hydrophilic compounds}

Both species showed the same composition in sugars and organic acids. Despite the significant differences $(p<0.001)$ found for all sugars (except for sucrose, $p=0.958$ ), the relative abundances followed the same order: fructose $>$ glucose $>$ sucrose $>$ trehalose (Table 1). Fructose was also reported as the main sugar in different Opuntia species. ${ }^{15}$ O. microdasys gave significantly higher contents in all sugars, except trehalose; however, its total sugars content $(9.6 \mathrm{~g} / 100 \mathrm{~g} \mathrm{dw})$ was lower than the quantified in cladodes of Opuntia ficus indica L. Miller from Mexico $(14.09 \mathrm{~g} / 100 \mathrm{~g} \mathrm{dw}) .^{16}$

The profiles in organic acids were also similar (Table 2) in both species, with malic acid as the major compound (24 g/100 g in O. macrorhiza; $8.9 \mathrm{~g} / 100 \mathrm{~g}$ in M. microdasys), followed by citric acid; on the other hand, ascorbic acid was the least abundant organic acid, in agreement with previous reports in Opuntia genus. ${ }^{1,5}$ Oxalic and quinic acids gave intermediate amounts, interchanging positions within species. With no exception, the quantities of each organic acid were significantly higher in the cladodes of Opuntia macrorhiza. These differences might be expected since the organic acids profile in plants depends upon the species, age and tissue type, while its accumulation is often modulated by the plant adaptation to specific environment conditions. ${ }^{17}$ 
Regarding the phenolic compounds, data of the retention time, $\lambda_{\max }$, pseudomolecular ion, main fragment ions in $\mathrm{MS}^{2}$, tentative identification and concentration of phenolic acid derivatives and flavonoids are presented in Table 3. An exemplifying HPLC phenolic profile, recorded at $370 \mathrm{~nm}$ and $280 \mathrm{~nm}$, is presented in Figure 1 for O. microdasys.

UV and mass spectra obtained by HPLC-DAD-ESI/MS analysis showed that the phenolic composition was characterized by the presence of phenolic acid (hydroxycinnamoyl and phenylpiruvoyl) derivatives, and flavonols. Sugar substituents consisted of hexoses and deoxyhexoses, as deduced from the losses of $162 \mathrm{Da}$ and $146 \mathrm{Da}$, respectively.

Peak 1 ([M-H] $]^{-}$at $m / z$ 255) could be associated to piscidic acid (Figure 1A). The observed fragments could be interpreted from the losses of carboxyl, carbonyl and hydroxyl functions, i.e., $m / z$ at $211\left(\left[\mathrm{M}-\mathrm{H}-\mathrm{CO}_{2}\right]^{-}\right), 193\left(\left[\mathrm{M}-\mathrm{H}-\mathrm{CO}_{2}-\mathrm{H}_{2} \mathrm{O}\right]^{-}\right), 179\left(\left[\mathrm{M}-\mathrm{H}-\mathrm{CO}_{2}-\mathrm{OH}-\mathrm{OH}\right]^{-}\right), 165$ ([M$\left.\left.\mathrm{H}-\mathrm{CO}_{2}-\mathrm{CO}-\mathrm{H}_{2} \mathrm{O}\right]^{-}\right)$and $149\left(\left[\mathrm{M}-\mathrm{H}-\mathrm{CO}_{2}-\mathrm{H}_{2} \mathrm{O}-\mathrm{CO}_{2}\right]^{-}\right)$. Similarly, peak $5\left([\mathrm{M}-\mathrm{H}]^{-}\right.$at $\mathrm{m} / z$ 239) was tentatively identified as eucomic acid (Figure 1B) considering the fragments at $\mathrm{m} / \mathrm{z} 195$ ([M-H-CO $]^{-}, 179\left(\left[\mathrm{M}-\mathrm{H}-\mathrm{CO}_{2}-\mathrm{OH}\right]^{-}\right), 149\left([\mathrm{M}-\mathrm{H}-\mathrm{CO}-\mathrm{OH}]^{-}\right)$and $133\left(\left[\mathrm{M}-\mathrm{H}-\mathrm{CO}_{2}-\mathrm{H}_{2} \mathrm{O}-\mathrm{CO}_{2}\right]^{-}\right)$. These compounds were only detected in O. macrorhiza, standing out among the major (piscidic acid: $3400 \mu \mathrm{g} / \mathrm{g}$ extract; eucomic acid: $1688 \mu \mathrm{g} / \mathrm{g}$ extract) phenolics detected herein. These acids had been previously reported in $O$. ficus-indica, ${ }^{18,19}$ and their occurrence seems restricted to plants exhibiting "crassulacean acid metabolism"; ${ }^{1}$ recently they have been found in relatively high amounts in extracts from juices of Opuntia spp. fruits. ${ }^{20}$

Peaks $2(649 \mu \mathrm{g} / \mathrm{g}$ extract in O. microdasys; $172 \mu \mathrm{g} / \mathrm{g}$ extract in O. macrorhiza) and 3 (381 $\mu \mathrm{g} / \mathrm{g}$ extract in $O$. microdasys), both showing the same pseudomolecular ion ([M-H] $\left.]^{-}\right)$at $m / z$ 341, were tentatively identified as two caffeic acid hexoside isomers, according to their characteristic UV spectra, showing maximum wavelength around $326 \mathrm{~nm}$, and to the ions at m/z $179\left(-162 \mathrm{mu}\right.$, loss of a hexosyl residue; [caffeic acid-H] $\left.{ }^{-}\right), 161$ ([caffeic acid- $\left.\left.\mathrm{H}_{-} \mathrm{H}_{2} \mathrm{O}^{-}\right]^{-}\right)$ and 135 ([caffeic acid- $\left.\left.\mathrm{CO}_{2}-\mathrm{H}\right]^{-}\right)$observed in their $\mathrm{MS}^{2}$ spectra. Similar reasoning can be 
applied to assign peak $4\left([\mathrm{M}-\mathrm{H}]^{-}\right.$at $m / z 325 ; 671 \mu \mathrm{g} / \mathrm{g}$ extract in O. microdasys $)$ as a coumaric acid hexoside, peak $6\left([\mathrm{M}-\mathrm{H}]^{-}\right.$at $\mathrm{m} / z$ 355; $852 \mu \mathrm{g} / \mathrm{g}$ extract in $O$. microdasys; $332 \mu \mathrm{g} / \mathrm{g}$ extract in O. macrorhiza) as a ferulic acid hexoside, and peak $8\left([\mathrm{M}-\mathrm{H}]^{-}\right.$at $m / z 385 ; 98 \mu \mathrm{g} / \mathrm{g}$ extract in O. macrorhiza) as a sinapic acid hexoside.

Peaks $7(435 \mu \mathrm{g} / \mathrm{g}$ extract in $O$. microdasys $)$ and $9(516 \mu \mathrm{g} / \mathrm{g}$ extract in O. microdasys; 244 $\mu \mathrm{g} / \mathrm{g}$ extract in O. macrorhiza), with the same pseudomolecular ion ([M-H] $]^{-}$at $\mathrm{m} / \mathrm{z} 489$ ), should also correspond to ferulic acid derivatives as revealed by the fragments at $\mathrm{m} / \mathrm{z} 193,175$ and 149; however, the nature of the substituents could not be established, thereby, their structures remain unknown.

Peak 10 showed a UV-vis spectrum with a shape suggesting a flavonoid derivative, however, we were unable to match a structure to its mass spectral characteristics. The remaining peaks 11-14 corresponded to flavonoids derived from three flavonol aglycones as deduced from their UV-vis and mass spectra, i.e., quercetin $\left(\mathrm{MS}^{2}\right.$ fragment at $m / z$ 301), kaempferol $\left(\mathrm{MS}^{2}\right.$ fragment at $m / z 285)$ and isorhamnetin $\left(\mathrm{MS}^{2}\right.$ fragment at $\left.m / z 315\right)$, which were previously reported to occur in Opuntia spp.. ${ }^{1}$ In all cases, a loss of $-454 \mathrm{mu}$, corresponding to two deoxyhexosyl (2x146 mu) and one hexosyl (162 mu) moieties, was produced from the respective pseudomolecular ion to yield the flavonol aglycone.

Flavonol bearing deoxyhexosylhexoside substituents have been reported to occur in different Opuntia species, namely rutinosides (i.e., rhamnosyl-glucosides) of quercetin and isorhamnetin. ${ }^{1}$ Furthermore, the presence of quercetin 3-O-rutinoside, kaempferol 3-Orutinoside and isorhamnetin 3-O-rutinoside has been positively identified in Opuntia microdays flowers in a recent study of our group. ${ }^{21}$ Thus, based on these precedents, the substituting sugars in the compounds detected in the present samples might be speculated to be rhamnose and glucose. On the other hand, in fresh stems of Opuntia dillenii, ${ }^{22}$ identified quercetin 3-O-(2'-rhamnosyl)rutinoside (manghaslin) (Figure 2C), which might well match 
with peak 11 in our samples, as only one fragment ion corresponding to the aglycone was observed in the $\mathrm{MS}^{2}$ spectrum, suggesting that the three sugars are constituting a trisaccharide. Similar structures might be assumed for peaks 12 and 14, which might be assigned as the respective $O$-(rhamnosyl)rutinosides of kaempferol and isorhamnetin. In the case of peak 13 the appearance of a fragment corresponding to the loss of a deoxyhexosyl moiety might suggest different locations for the deoxyhexose and the deoxyhexosylhexose substituents, so that it might be interpreted as an isorhamnetin $O$-rhamnoside- $O$-rutinoside derivative. This latter compound was also detected in the flowers of Opuntia microdays by our group. ${ }^{21}$ Nevertheless, the identities proposed for peaks 11-14 must be considered merely tentative, as the data obtained in the present study do not allow us to conclude about the actual nature and position of the sugar substituents of the compounds.

Overall, the phenolic profiles of each cladode showed significant differences, with 10 compounds (6 phenolic acid derivatives and 4 flavonols) in O. microdasys and 7 compounds (6 phenolic acid derivatives and 1 flavonol), and only four compounds detected simultaneously in both species. Piscidic (1) and eucomic acid (5) were the main phenolic compounds in $O$. macrorhiza, while isorhamnetin $O$-(rhamnosyl)rutinoside (14) was the most abundant in O. microdasys.

\section{Chemical composition in lipophilic compounds}

Besides the fatty acids included in Table 4, caproic acid (C6:0), caprylic acid (C8:0), capric acid (C10:0), tridecanoic acid (C13:0), eicosenoic acid (C20:1) and cis-11,14-eicosadienoic acid (C20:2) were also quantified, but in amounts below $0.2 \%$. The characterized profiles were quite similar for both Opuntia samples, except for C20:5, which was only detected in $O$. macrorhiza. Linoleic acid (C18:2) was the major fatty acid, followed by palmitic acid (C16:0), behenic acid (C22:0), lignoceric acid (C24:0) and linolenic acid (C18:3). 
Nevertheless, the relative percentages of each quantified fatty acid showed always (except for $\mathrm{C} 15: 0$ and $\mathrm{C} 20: 3+\mathrm{C} 21: 0)$ statistically significant differences among both species. The saturated fatty acids (SFA) were predominant $(61 \%$ in $O$. microdasys and $56 \%$ in $O$. macrorhiza), especially due to the contents in C16:0 and C22:0, being also detected relatively high percentages (33\% in O. microdasys and $36 \%$ in O. macrorhiza) of polyunsaturated fatty acids (PUFA), mainly due to C18:2 and C18:3. PUFA are generally recognized as healthpromoting nutrients, specifically to prevent cardiovascular diseases, autoimmune disorders, diabetes and other diseases. ${ }^{23}$ The MUFA levels lay below $8 \%$ in both species, with C18:1 as the major component. The fatty acids profiles are in general agreement with the findings reported in the cladodes ${ }^{24}$ and flowers ${ }^{25}$ of Tunisian varieties of Opuntia genus.

Concerning tocopherol composition, $O$. mycrodasiys gave significantly higher amounts of all the quantified isoforms (Table 5). $\alpha$-Tocopherol was the prevailing isoform in both species (5.3 mg/100 g in O. mycrodasiys; $4.9 \mathrm{mg} / 100 \mathrm{~g}$ Opuntia macrorhiza), while $\delta$-tocopherol was only detected in $O$. mycrodasiys. The levels of tocopherols are often related with high percentages in PUFA, due to their effectiveness as lipophilic antioxidants. ${ }^{26}$

\section{Evaluation of bioactive properties}

The cladodes of $O$. macrorhiza presented the highest antioxidant activity for all the performed assays (Table 6). The $\mathrm{EC}_{50}$ values calculated for DPPH scavenging activity (O. microdasys: $1.00 \mathrm{mg} / \mathrm{mL}$; O. macrorhiza: $0.89 \mathrm{mg} / \mathrm{mL})$, reducing power (O. microdasys: $1.11 \mathrm{mg} / \mathrm{mL} ; O$. macrorhiza: $0.60 \mathrm{mg} / \mathrm{mL})$, inhibition of $\beta$-carotene bleaching $(O$. microdasys: $0.13 \mathrm{mg} / \mathrm{mL}$; O. macrorhiza: $0.09 \mathrm{mg} / \mathrm{mL})$ and TBARS inhibition capacity $(O$. microdasys: $0.11 \mathrm{mg} / \mathrm{mL}$; O. macrorhiza: $0.06 \mathrm{mg} / \mathrm{mL}$ ) were significantly lower for $O$. macrorhiza, probably due its higher content in hydrophilic phenolic compounds (Table 3) and organic acids (Table 2). In general, in the evaluation of the antioxidant properties, antioxidant activity is under the 
influence of extract's phenolic composition, ${ }^{27,28}$ and a higher level of phenols usually resulted in a higher antioxidant capacity. It is true that $O$. microdasys presented higher contents in tocopherols, which are also antioxidant compounds, but the differences were less significant.

\section{Conclusion}

The assayed botanical parts (cladodes) of O. microdasys and O. macrorhiza showed a rich composition in different hydrophilic and lipophilic compounds. Interestingly, and despite the phylogenetic proximity and similarity in the edaphoclimatic conditions where the samples were obtained, both Opuntia species revealed significant differences in the assayed components. Overall, fructose, glucose, C6:0, C8:0, C12:0, C14:0, C14:1, C16:0, C18:3, C20:0, C22:0, C23:0, C24:0, SFA, tocopherols and DPPH $\mathrm{EC}_{50}$ values were significantly higher in O. microdasys; on the other hand, trehalose, organic acids, C13:0, C16:1, C17:0, C18:0, C18:1, C20:1, C20:2 and MUFA were significantly higher in O. macrorhiza. Hence, the elucidation of the most abundant compounds might constitute useful information to select the best species regarding a determined application of its natural extracts/isolated compounds.

\section{Competing interests}

The authors declare no competing financial interest.

\section{Acknowledgements}

The authors are grateful to Fundação para a Ciência e a Tecnologia (FCT, Portugal) for financial support to CIMO (strategic project PEst-OE/AGR/UI0690/2011). J.C.M. Barreira thanks FCT, POPH-QREN and FSE for his grant (SFRH/BPD/72802/2010). L. Barros thanks “Compromisso para a Ciência 2008” for her contract. The GIP-USAL is financially supported 
by the Spanish Government through the Consolider-Ingenio 2010 Programme (FUN-CFOOD, CSD2007-00063).

\section{References}

1 F.C. Stintzing, R. Carle, Mol Nutr Food Res, 2005, 49, 175-194.

2 M. Espino-Díaz, J. de Jesús Ornelas-Paz, M.A. Martinéz-Téllez, C. Santillán, G.V. Barbosa-Cánovas, P.B.Zamudio-Flores, G.I. Olivas, J Food Sci 2010, 75, E347-E352.

3 M.A. Ayadi, W. Abdelmaksoud, M. Ennouri, H. Attia, Ind Crop Prod, 2009, 30, 4047.

4 M.R. Vignon, L. Heux, M.E. Malainine, M. Mahrouz, Carbohydr Res, 2004, 339, 123 131.

5 JM Feugang, P Konarski, D Zou, FC Stintzing, C Zou, Front Biosc, 2006, 11, 25742589 .

6 F.C. Stintzing, R. Carle, Trends in Food Sci Technol, 2007, 18, 514-525.

7 M.-E. Malainine, A. Dufresne, D. Dupeyre, M. Mahrouz, R. Vuong, M.R. Vignon, Phys Chem News, 2001, 1, 126-30.

8 S.P. Nobel, A.A. Israel, J Exp Bot, 1994, 45, 295-303.

9 D.-M. Zou, M. Brewer, F. Garcia, J.M. Feugang, J. Wang, R. Zang, H. Liu, C. Zou, Nutr J, 2005, 4, 25.

10 L. Tesoriere, D. Butera, A.M. Pintaudi, M. Allegra, M.A. Livrea, Am J Clin Nutr, 2004, 80, 391-395.

11 M. Maffei, M. Meregalli, S. Scannerini, Biochem Syst Ecol 1997, 25, 241-253.

12 C. Pereira, L. Barros, A.M. Carvalho, I.C.F.R. Ferreira, Food Res Int 2011, 44, $2634-$ 2640.

13 L. Barros, C. Pereira, ICFR Ferreira, Food Anal Method, 2013, 6, 309-316 
14 A. Martins, L. Barros, A.M. Carvalho, C. Santos-Buelga, I. P. Fernandes, F. Barreiro, I. C. F. R. Ferreira, Food Funct., 2014, 5, 1091-1100.

15 B.G. Sutton, U.P. Ting, R. Sutton, Plant Physiol, 1981, 68, 784-787.

16 E. Ramírez-Moreno, D. Córdoba-Díaz, M.C. Sánchez-Mata, C. Díez-Marqués, I. Goñi, Food Sci Technol, 2013, 51, 296-302.

17 J. López-Bucio, M.F. Nieto-Jacobo, V. Ramírez-Rodríguez, L. Herrera-Estrella, Plant Sci, 2000, 160, 1-13.

18 A. Nordal, J. Gether, G. Haustvei, L.A. Kristiansen, J. Brunvoll, E. Bunnenberg, C. Djerassi, R. Records, Acta Chem Scandinav, 1996, 20, 1431-1432.

19 F.F.F. Teles, J.W. Stull, W.H. Brown, F.M. Whiting, J Sci Food Agric, 1984, 35, 421425.

20 A.T. Serra, J. Poejo, A.M. Matias, M.R. Bronze, C.M.M. Duarte, Food Res Int, 2013, $54,892-901$.

21 H. Chahdoura, JCM Barreira, L. Barros, C. Santos-Buelga, I.C.F.R. Ferreira, L. Achour, J Funct Food, 2014, 9, 27-37.

22 Y. Qiu, Y. Chen, Y. Pei, H. Matsuda, M. Yoshikawa, Chem Pharm Bull, 2002, 50, $1507-1510$.

23 M.A. McGuire, M.K. McGuire, J Anim Sci, 2000, 77, 1-8.

24 S. Abidi, B. Salem, V. Vasta, A. Priolo, Small Ruminant Res, 2009, 87, 9-16.

25 I. Ammar, M. Ennouri, B. Khemakhem, T. Yangui, H. Attia, Ind Crop Prod, 2012, 37, $34-40$.

26 L. Packer, J. Fuchs, (Eds.), Vitamin E in Health and Disease, Marcel Dekker, New York, 1993, pp. 1-1000.

27 L.M. Cheung, P.C.K. Cheung, VEC Ooi, Food Chem, 2003, 81, 249-255. 
28 H. Dib, M.C. Beghdad, M. Belarbi, M. Seladji, M. Ghalem, Int J Med Pharmaceut Sci, 2013, 3,147-158. 
Table1. Sugars composition (g/100 g dw) of Opuntia microdasys and Opuntia macrorhiza cladodes. Results are presented as mean \pm SD.

\begin{tabular}{lcccc}
\hline & Levene's test & Opuntia microdasys & Opuntia macrorhiza & $t$-test $(\mathrm{n}=9)$ \\
\hline Fructose & $p=0.179$ & $4.7 \pm 0.1$ & $2.9 \pm 0.1$ & $p<0.001$ \\
Glucose & $p=0.476$ & $3.6 \pm 0.1$ & $2.4 \pm 0.1$ & $p<0.001$ \\
Sucrose & $p=0.310$ & $0.9 \pm 0.1$ & $0.9 \pm 0.1$ & $p=0.958$ \\
Trehalose & $p=0.017$ & $0.37 \pm 0.03$ & $0.57 \pm 0.02$ & $p<0.001$ \\
Total sugars & $p=0.516$ & $9.6 \pm 0.2$ & $6.9 \pm 0.2$ & $p<0.001$ \\
\hline
\end{tabular}


Table 2. Organic acids composition (g/100 g dw) of Opuntia microdasys and Opuntia macrorhiza cladodes. Results are presented as mean \pm SD.

\begin{tabular}{lcccc}
\hline & Levene's test & Opuntia mycrodasiys & Opuntia macrorhiza & $t$-test $(\mathrm{n}=9)$ \\
\hline Oxalic acid & $p=0.003$ & $0.084 \pm 0.002$ & $0.30 \pm 0.01$ & $p<0.001$ \\
Quinic acid & $p<0.001$ & $0.053 \pm 0.001$ & $0.41 \pm 0.01$ & $p<0.001$ \\
Malic acid & $p=0.002$ & $0.69 \pm 0.01$ & $2.0 \pm 0.2$ & $p<0.001$ \\
Ascorbic acid & $p=0.007$ & $0.0061 \pm 0.0001$ & $0.017 \pm 0.002$ & $p<0.001$ \\
Citric acid & $p=0.001$ & $0.58 \pm 0.01$ & $1.3 \pm 0.2$ & $p<0.001$ \\
Total organic acids & $p=0.002$ & $1.41 \pm 0.02$ & $4.1 \pm 0.3$ & $p<0.001$ \\
\hline
\end{tabular}

